\title{
An Online Platform for Connecting NGO
}

\author{
Ms. Snehal Chaudhari ${ }^{1}$, Ms. Sneha Dighe ${ }^{1}$, Ms. Rucha Desai ${ }^{1}$, Ms. Sofiya Mulla ${ }^{1}$, Mrs. Yugchhaya Dhote $^{1}$ \\ V.E.S Institute of Technology, Chembur, Mumbai University, India ${ }^{1}$
}

\begin{abstract}
Paper proposes an online web portal which will be looked up as a hub for non-Government organizations and their needs. The main advantage of developing such portal is to remove the tedious task of NGO's of finding donors or finding volunteers in order to fulfill the requirement of NGO. Another advantage is that we can easily find NGO or volunteer over the Internet rather than a manual system such as by giving an advertisement in Newspaper etc. It will be also beneficial for not only to the volunteers or donors, but also for the NGOs and conducting other social events such as Blood donation campaign, Awareness Workshops etc. It will also give ease in maintaining records. Overall it will prove as an essential tool for the smooth functioning of the NGOs and a great assistance for its users.
\end{abstract}

Keywords: Common platform for NGO, Online NGO organizing, Small-scale industry, Crowdfunding.

\section{INTRODUCTION}

Information technology has progressed to such an extent where people do the daily work with just few clicks. The advancement in technology has led the world where it is today. Just a few clicks and all the information from around the world is present in the hands of people within fraction of seconds. Similarly, people don't find time to do some duties out of the daily working schedules and this is where our paper focuses on.

Today there are many such people who want to help others in some good cause or for self -satisfaction. Donation or volunteering is one of the most preferred things which people wish to do. But searching for a satisfactory NGO becomes a tedious task. Thus our online application will be able to provide a solution to the previous mentioned burden.

Our research brought us to a conclusion that there should be such a system where people may go through a good number of NGOs and make a particular selection according to their need instead of being overwhelmed by the search results which internet provides.

This system will not only be able to assist the donors or the volunteers but also allow the NGOs or social events to advertise themselves through our application. All the NGOs will have their own web pages displaying their information and contacts. The NGOs will also be able to upload their wish lists according to their current needs so that the donor will be able to view them and contact the particular NGO. Hence the overall paper proposes such a system that will soothe the on goings between a donor/ volunteer and an NGO/social organization.

\section{LITERATURE SURVEY}

According to NON-GOVERNMENT ORGANIZATIONS: PROBLEMS \& REMEDIES IN ,it is a usual lesson that there have been grave charges of mistreat and misuse of funds received as grant- in-aid form the government, overseas donors and brought up through their own resources by the many of the NGOs.

According to Online Monitoring System (OMS)], help the NGOs to centrally monitor and track the progress of their daily work in a very comprehensive manner.

According to Assessing Online Behaviours through Discussion Forums in NGO's Daily Working Life [2], it was found that a shortage of resource is often experienced by the social and welfare institutions because their service focus is on the under privileged rather than the opposite.

The paper, an introduction to NGO management [5], suggests the growing need of NGO throughout the world be more effective and productive, and one way to achieve this is by broadening and strengthening the constitution of their Boards.

The paper, Environmental NGOs in World Politics Linking the Local and the Global [6], explains the key role of NGOs in an emerging world environmental politics, this paper also shows how NGOs act both as independent bargainers and as agents of social learning, to link biophysical conditions to the political realm at both the local and global levels.

The paper, NGOs Intervention in Poverty Alleviation [7], D.K. Gosh (2001) opines that attacking poverty and its reduction to an appreciable extent seems to be not manageable only by the Government sector. According to eighth 
paper, The National Non-profit Leadership and Management Journal [8], their purpose is to present a corporate bridge for a win-win situation and achieve a balance in society by studying the existing operations of the NGOs.

The paper, Development and Urban Social Change: women's community action in global cities [9], begins with the assumption that gender, like other constructs such as race, class, sexuality, religion and nationality, fundamentally shapes the social order in which people live, and therefore deserves attention as a category of analysis.

The paper, Government Non-profit Relations in the Modern Welfare State [10], Salamon, L. M. Partners in Public Service demonstrates, the growth of the public sector has been matched by a proportionate increase in the size and importance of the non-profit sector.

The paper, NGOs and Women Development in Rural South India [11], evaluates and compares the role of two NGOs i.e., Integrated Development Service and Gram Vikas in promoting women development.

In paper, The Role of NGOs and Training Institution in DWCRA [12], Vijay Mahajan (1994) made an attempt to examine the role of NGOs and training institutions in DWCRA programme.

In paper, NGO CONNECT [13], Authors found that NGO CONNECT is web portal for serving various services such as common platform for various NGO, Interested volunteer can register for work which can be conducting workshop or helps in conducting particular event.

\section{IMPLEMENTATION}

NGO_CONNECT is the web portal which is common platform for different categories of NGO's and other social organizations. Not only NGO's and social organizations but also volunteers and donors are connecting to each other for good cause.

\subsection{NGO}

\subsubsection{NGO Registration}

NGO registration allows NGOs to enter their basic information like username, password, address, contact, and city. It also allows entering some important fields such as type of clause the NGO supports or website address this is for redirecting the NGO profile visitors to directly that particular NGO website.

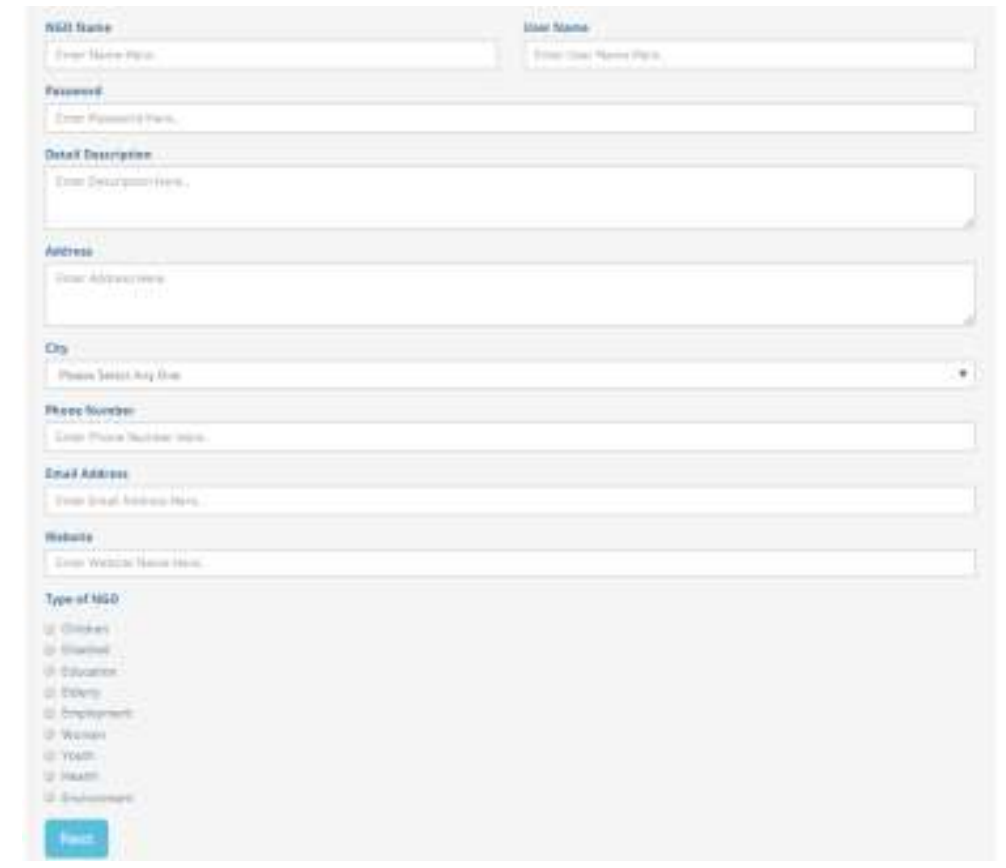

Fig 1: NGO Registration

\subsubsection{NGO List}

NGO tab displays all the registered NGOs on NGO_CONNECT. All these NGOs are displayed according to their cause i.e. children welfare, education, elderly etc. It behaves like a filter for the people who are interested in a particular cause only. 


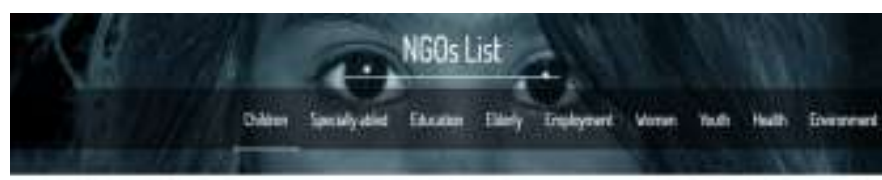

\section{Akshara Centre Annamrita-15KCON Antarang Apnalaya

Food Rel Foundation foundation

Fig 2: NGO List

\subsubsection{NGO Profile}

Whenever user needs to get all the details of a particular NGO, the user just needs to click the link of that NGO and the profile page pops up. This page shows all the details of the NGO that is entered during the NGO registration. Whenever an NGO's profile is opened, the page hit of that NGO is counted. Here there are 2 important options:

1. Interested: When this button is clicked, the particular NGO's interested count is increased by one. This count is displayed on that NGO's dashboard.

2. Give Feedback: Here any volunteer who has worked in that particular NGO can give feedback about that NGO. This feedback is directed to the NGO's admin on the NGO dash-board. This feedback acts as an improvement for the NGOs if required.

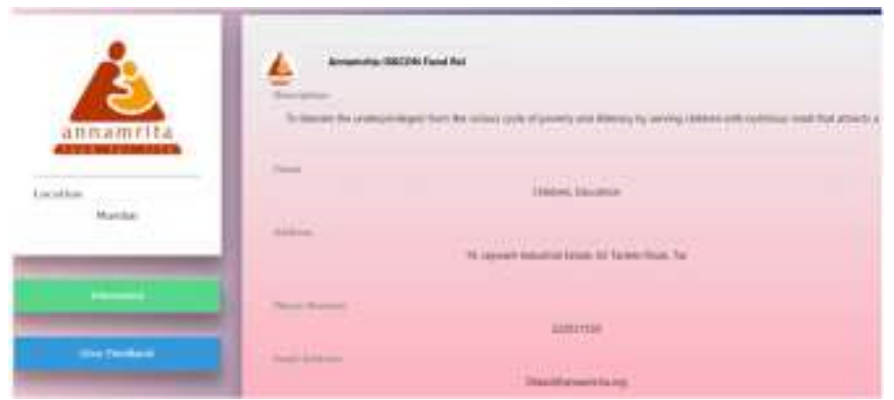

Fig 3: NGO Profile

\subsubsection{NGO Dashboard}

\section{Admin Dashboard}

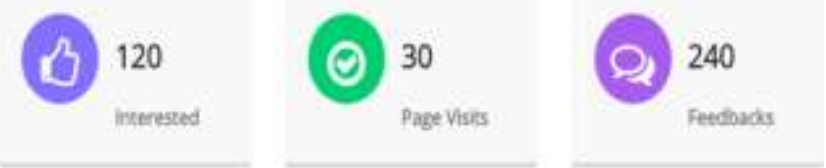

Fig 4: Admin Dashboard

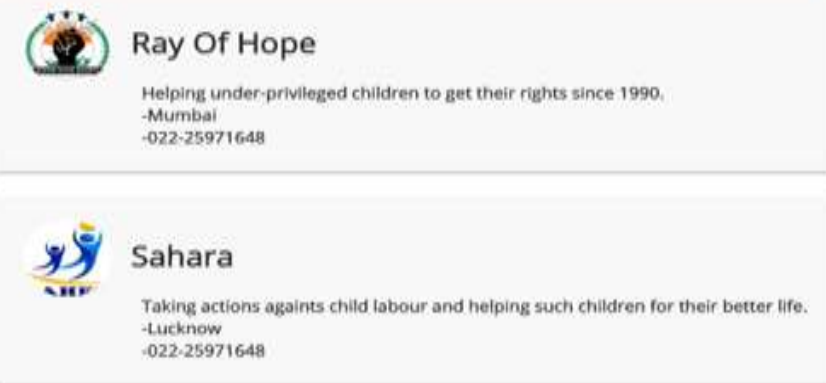

Fig 5: Suggested NGO 
It provides NGOs with their own dashboards allowing NGO admins to update goods and monetary wish lists. Ngoconnect also facilitate to change details for a specific type of volunteer based on work timings and workshops. Maximum five suggestions of similar NGOs around are provided on the dashboard. This feature helps the NGOs to get over any organisational problems or if they face any issues and need help of similar NGOs. A facility to improve the NGOs by directing feedbacks from previous volunteers who have worked at the NGO has also been included. It also provides the count of page hits and interested volunteers to access the overall ranking of the NGOs.

\subsubsection{NGO Wish-List}

Each NGO is provided with three types of wish lists where the admin can specifyits needs. Their needs can be in the form of goods, monetary or volunteers.

In goods wish-list NGO can add required item and its quantity with priority.Similarly in monetary wish-list NGO can add cause and amount required with priority.

Priority specifies the level of urgency. Which can be specified as High, Medium and Low, The wish list will be displayed in an increasing order of priority.

They are provided with additional Volunteer wish list, wherein admin can specify the type of volunteer which are - Full time, part time and for holding workshops.

\section{Manage Wishlists}

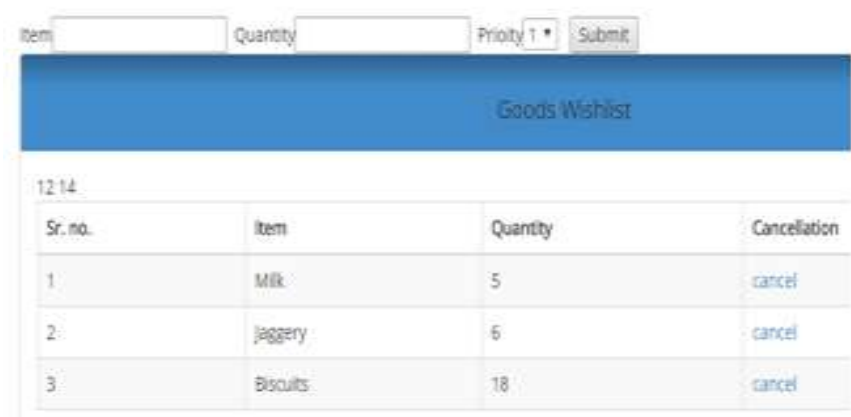

Fig 6: Manage Wish list

\subsection{VOLUNTEER}

3.2.1 Volunteer Registration

Volunteer registration too takes all the basic details of the volunteers like username, password, address etc. The important details which are taken during registration is the type of NGO in which the person would like to volunteer. The volunteer can enter time, type of work and city preferences.

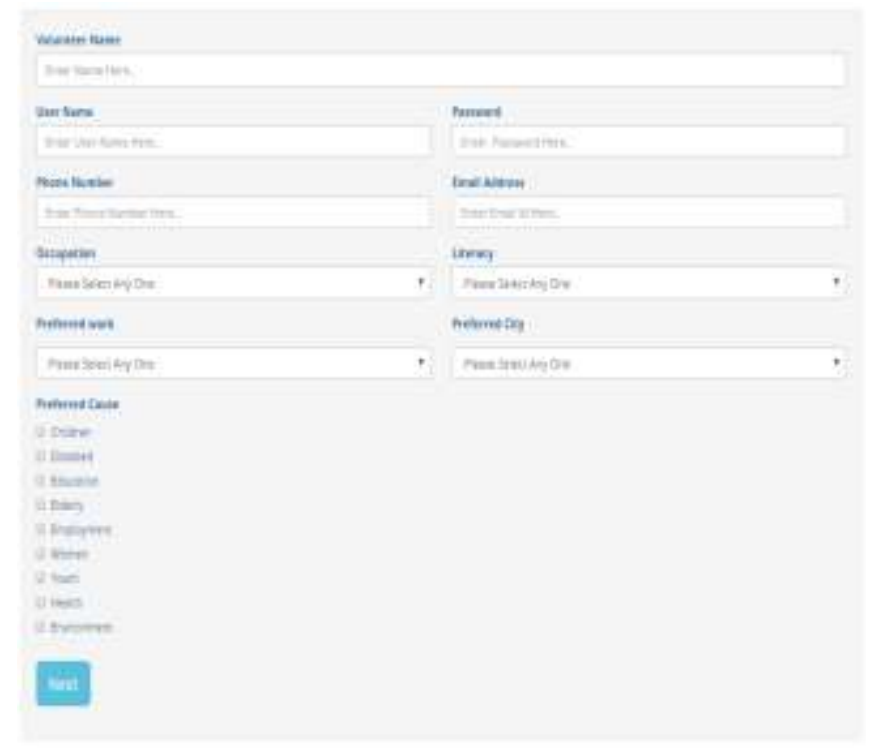

Fig 7: Volunteer Registration Form 


\subsubsection{Volunteer Dashboard}

The volunteer dashboard consists of 3 main tabs namely: My profile, suggested NGOs, edit profile etc. All the details of volunteer taken during registration are displayed in the My Profile tab. The most important tab in the volunteer dashboard is the Suggested NGOs tab in which all the NGOs matched according to the volunteer's profile are listed. The volunteer can click on any link of the displayed suggestions to go through the complete profile of the NGO. The next tab is Edit Profile. As the name suggests, the volunteer can edit his/her profile.

\subsection{DONATION}

Sometimes people don't wish to give money instead they believe in donating actual goods to the needy. That is why the web portal provides options to donate either goods or money.

On clicking Goods or Money donations tab a corresponding list of NGO's with their requirement is displayed. The list is displayed according to the priority given by NGO's.

\subsection{EVENT}

On the home page, upcoming events related to a social cause are shown. This can be added by anyone by filling the form present on a home page, but before any particular event details are shown on web portal its cross verified by the administrator of the web site. In verification validity of event and authority of organizer of the event is checked.

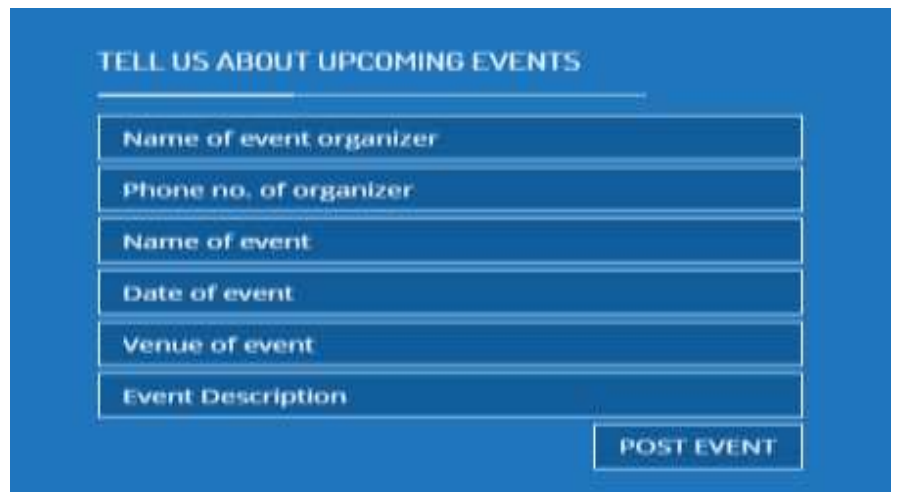

Fig 8: Event Registration Form

\section{TECHNICAL SPECIFICATION}

Web portal is implemented in two parts. One is Front end and other is Back end. Front is implemented using languages such as HTML, CSS, JavaScript etc. To support backend XAMPP is used. Back end can be implemented using MySQL and PHP. Web portable is very user friendly; any user can easily interact with system with much ease. Data access permission is different for different user i.e. admin have different rights and the user who can only able to see front end have different rights. Matching technique is used for matching volunteer profile with NGO needs and as per match results are fetched. Implemented web portal will easily work on Laptop, PC, Tablet, etc.

\section{CONCLUSION}

In this paper we gave the implementation idea of web portal which provides the various services to the user, donor, volunteer, NGO etc., such as NGO can add the things that they want to buy from anything, if anyone is interested in any kind of donation as per requirements of that particular NGO then they can donate as per the information flow provided. If anyone is interested in conducting workshop or teaching to people about awareness or general things then they can create there profile and according to that profile available options get displayed. This portal acts as a mediator to serve such various kinds of facilities to their end users.

\section{FUTURE SCOPE}

\subsection{Crowd funding:}

Crowdfunding can be used for raising money from a large number of people through Internet and later distribute that money among the needy.

\subsection{Data Analysis:}

Data analysis is useful for search by name or using any keyword i.e., portal will work as search engine. 


\subsection{Employment:}

Today many people are unemployed so through this web portal various industries can offer support for such people by giving them work.

7.4 Small Scale Industry:

Portal can also be extended to provide support for small scale industries such as sewing industry etc.

\section{ACKNOWLEDGEMENT}

We would like to take this opportunity to thank our mentor and project guide, Mrs. Yugchhaya Dhote, Assistant teacher of the Department of Computer Engineering at VESIT, for her continued support and guidance.

\section{REFERENCES}

[1.] "Numeric Paper Forms for NGOs", by Gursharan Singh, Leah Findlater, Kentaro Toyama, Scott Helmer, Rikin Gandhi, RavinBalakrishnan

[2.] “Assessing Online Behaviors through Discussion Forums in NGO's Daily Working Life”, by Yao-Jen Chang, Yu-Chia Chuang, Tsen-Yun Wang, Yao-Sheng Chang

[3.] "Online Monitoring System(OMS) ,an Online tool for centralized monitoring of NGOs”, by Ravi Shankar, VIT University ,Vellore, India and Narita ,School of Information Technology and Engineering

[4.] "NON-GOVERNMENT ORGANIZATIONS: PROBLEMS \& REMEDIES IN INDIA", by KakumaniLavanya and Lathaand Kotte Prabhakar Ellison, M. Firm foundations: Improving NGO data collection

[5.] "An introduction to NGO Management" (Iranian Studies Group at MIT) June 2005

[6.] "Environmental NGOs in World Politics Linking the Local and the Global”, by T. Princen and M. Finger (1994)

[7.] "NGOs Intervention in Poverty Alleviation", By Ghosh, D.K. (2001), Kurukshetra, March.

[8.] "The National Non-profit Leadership and Management Journal", Volume 18, Number 1, January/February 2000.

[9.] "Development and Urban Social Change: women's community action in global cities", by Lind And A. Gender

[10.] "Government Non-profit Relations in the Modern Welfare State", by The Johns Hopkins University Press. 1995 by Salamon, L. M. Partners in Public Service

[11.] "NGOs and Women Development in Rural South India", A Comparative Analysis, Vistaar Publications, New Delhi by Vanitha, V (1993)

[12.] "The Role of NGOs and Training Institution in DWCRA", NIRD, Hyderabad, by Vijay, M(1994)

[13.] "NGO CONNECT" by SnehalChaudhari,SnehaDighe, Rucha Desai, SofiyaMulla, Yugchhaya Dhote (2017) 